\title{
Produção de narrativas digitais através do Scratch como estratégia de pesquisa e ação para o Orientador Educacional
}

\author{
Claudia da Silva Gomes - Universidade Federal do Rio Grande do Sul - \\ claug@ufrgs.br - https://orcid.org/0000-0001-9215-9358 \\ Silvana Corbellini - Universidade Federal do Rio Grande do Sul - \\ silvanacorbellini@gmail.com - http://orcid.org/0000-0002-3335-0387
}

\begin{abstract}
Resumo: A produção de narrativas digitais com Scratch $^{1}$, sob função pedagógica e diagnóstica pelo orientador educacional é uma estratégia ainda pouco utilizada no contexto escolar. Este trabalho reporta uma prática que pretendeu identificar como o horizonte escolar no ano inicial da pandemia da COVID 19 foi percebido por discentes e, ainda, investigar possibilidades de ações do $\mathrm{OE}^{2}$, baseadas em investigação. Através de um estudo de caso com narrativas em Scratch, alunos da $\mathrm{EB}^{3}$ manifestaram suas percepções escolares antes e durante a pandemia, assim como suas projeções de um futuro pós-pandemia. A partir da análise de conteúdo, a pesquisa evidenciou os sentimentos discentes em relação à vida escolar, de baixa à média perspectiva em relação às suas práticas e aprendizagens; alta compreensão em relação às medidas de prevenção da COVID 19 e oportunidades de ação do OE, na medida em que, através da atividade, demandante de vários níveis de abstração, há a exploração da cultura digital, a viabilização de um canal de escuta e exploração de conteúdos escolares e oportunidades de ação. Constatou-se que a temática viabiliza um trabalho integrado entre discentes, docentes e orientadores educacionais, além de contribuir como instrumento diagnóstico para demais profissionais da área da educação e da saúde.
\end{abstract}

Palavras-chave: Orientação educacional. Scratch. Narrativas digitais. Instrumento Diagnóstico.

\section{Digital narrative production through Scratch as a research strategy and action for the Educational Advisor}
Claudia da Silva Gomes - Universidade Federal do Rio Grande do Sul - claug@ufrgs.br - https://orcid.org/0000-0001-9215-9358
Silvana Corbellini - Universidade Federal do Rio Grande do Sul - silvanacorbellini@gmail.com - http://orcid.org/0000-0002-3335-0387

\begin{abstract}
The production of digital narratives with Scratch, under pedagogical and diagnostic function by the educational advisor is a strategy still little used in the school context. This paper reports on a practice that aimed to identify how the school horizon in the initial year of the COVID 19 pandemic was understood by students, and also to
\end{abstract}

\footnotetext{
${ }^{1}$ Trata-se de um ambiente virtual de programação baseado na linguagem Logo. Uma plataforma colaborativa gratuita do grupo Lifelong Kindergarten Group do Media Lab do MIT (Instituto de Tecnologia de Massachusets), disponível em https://scratch.mit.edu/

${ }^{2}$ Acrônimo de Orientador Educacional.

${ }^{3}$ Refere-se à Educação Básica, primeira etapa do sistema de educação no Brasil.
} V. $19 \mathrm{~N}^{\mathrm{o}} 1$, julho, 2021 
investigate possibilities for EG actions based on research. Through a case study with narratives in Scratch, BE students expressed their school perceptions before and during the pandemic, as well as their projections of a post-pandemic future. From the content analysis, the research showed the students' feelings regarding school life, from low to medium perspective regarding their practices and learning; high understanding regarding COVID 19's prevention measures; and EG's opportunities for action, to the extent that through the activity, which demands several levels of abstraction, there is the exploration of the digital culture, the feasibility of a channel for listening and exploring school contents, and opportunities for action. It was found that the theme enables integrated work among students, teachers, and educational advisors, besides contributing as a diagnostic tool for other professionals in education and health.

Keywords: Educational Guidance. Scratch. Digital Narratives. Diagnostic Instrument.

\section{Introdução}

A escola, na atualidade, necessita conectar-se às culturas emergentes, inovando e diversificando suas práticas pedagógicas. A tão almejada qualidade nos sistemas de educação perpassa, entre outros fatores, a motivação e a escuta atenta dos públicos envolvidos para o melhor estabelecimento das práticas de ensino e aprendizagem. $\mathrm{O}$ ano pandêmico da COVID-19 - 2020 - ano atípico, especificamente em seu primeiro semestre impactou o calendário letivo brasileiro, sendo executado presencialmente, em média, apenas em seus trinta dias iniciais. A adoção de políticas de distanciamento ou isolamento social em razão do alto risco de contágio e propagação do vírus entre humanos, fez com que o contato entre o ambiente escolar e seus alunos passasse a ser realizado quase que, exclusivamente, de forma virtual. Entre as tantas necessidades excepcionais de reinvenção e inovação, a escola e seus públicos sofreram grandes impactos.

A Orientação Educacional, amparada em lei desde 1968, é uma atividade que almeja a qualificação do processo de ensino e aprendizagem. Tem como objeto da atividade a assistência ao educando, visando o desenvolvimento integral e harmonioso de sua personalidade, ordenando e integrando os elementos que exercem influência em sua formação e preparando-o para o exercício das opções básicas. (Brasil, 1973). Para Pascoal et al. (2008, p. 118) o OE pode ser um profissional da educação que elucida fatores presentes no cotidiano escolar e impactantes na aprendizagem, o que evidencia uma dimensão pedagógica da atividade. Os educadores, onde incluem-se os orientadores educacionais, são peças-chave na compreensão e balizamentos possíveis para o melhor desenvolvimento da sociedade. E, quando falamos em desenvolvimento, se faz necessário pensarmos em seu sentido amplo, integral dos sujeitos. Pensarmos em processos de ensino e aprendizagem que afetem positivamente os sujeitos, instigando a curiosidade, a promoção de pesquisas, a criticidade e, principalmente, o despertar da percepção de que são sujeitos capazes de concretização de seus projetos. (Bock, 2009)

Nas instituições escolares, a Base Nacional Comum Curricular (BNCC) norteia o currículo e o Projeto Político Pedagógico e, na atualidade, Tecnologia e cultura digital e Projeto de vida já se encontram entre as competências a serem desenvolvidas, ou seja, estão previstas no rol de "mobilização de conhecimentos (conceitos e procedimentos), habilidades (práticas, cognitivas e socioemocionais), atitudes e valores para resolver demandas complexas da vida cotidiana, do pleno exercício da cidadania e do mundo do trabalho" (Brasil, 2020). Desta forma, o documento procura equacionar os conhecimentos escolares aos da vida em sociedade, imersos em um mundo diverso em possibilidades. Nesse sentido, cabe destacar que as competências não se constituem como disciplinas no 
currículo, mas como um norte de intencionalidade, de construção contínua e diária, contribuindo para a formação de um sujeito cidadão (Corbellini, 2020, p. 119).

Especialmente, sob o aspecto tecnológico, a pandemia, além de evidenciar ainda mais as lacunas escolares quanto ao emprego de tecnologias em atividades didáticopedagógicas, as demandou sobremaneira. No entanto, também oportunizou aprendizagens diferenciadas ou mesmo reconfigurações em seus usos. Em alguns casos, a exemplo do trabalho do OE, o emprego de tecnologias digitais pode ser adaptado e experimentado, de forma a conceber ferramentas auxiliares potentes para $\mathrm{o}$ desenvolvimento integral dos sujeitos e, fundamentalmente, articuladas com os públicos escolares.

Na pesquisa realizada, acreditou-se que o investimento na promoção de narrativas digitais poderia propiciar a abertura de canais para a escuta de discentes por parte dos orientadores educacionais. Uma prática investigativa e, ao mesmo tempo pedagógica, na medida em que associa a escuta, a atividade pedagógica munida de tecnologia digital demandante de diferentes níveis de abstração e conteúdos escolares diversos.

Diante disso, a pesquisa assumiu como objetivos: a identificação da percepção do horizonte escolar no ano de 2020, sob a perspectiva discente; a investigação acerca das possibilidades de ações emergentes para o OE e o uso do Scratch como possibilidade de investigação do OE. Além disso, objetivou-se contribuir para o desenvolvimento e implementação de práticas pedagógicas intencionalmente munidas com ferramentas tecnológicas. A seguir, na sessão dois, será apresentado o método de pesquisa empregado; na sessão três a demonstração e discussão dos resultados e, por fim, as considerações finais.

\section{Método de pesquisa}

A pesquisa científica visa a conhecer, de forma sistemática, metódica e crítica, um ou mais aspectos de determinado assunto, tensionando o avanço do conhecimento humano (Pradanov, 2013). De natureza aplicada, o presente estudo pretendeu a geração de dados científicos para auxílio de ordem prática, no sentido de sanar o problema de pesquisa: como a confecção de narrativas digitais pelos discentes durante a pandemia pode subsidiar práticas de ação para o orientador escolar? Quanto aos seus objetivos, estes se constituíram pela identificação sobre como o horizonte escolar no ano de 2020 foi percebido por discentes e pela investigação das possibilidades de desenvolvimento de ações do OE baseadas em investigação. Assim, em conformidade com Gil (1991), o estudo abarca a pesquisa exploratória, ao intentar a identificação de ações emergentes para o $\mathrm{OE}$, a partir das produções discentes, contribuindo para um melhor delineamento e formulação de hipóteses para ações pedagógicas escolares. Cabe lembrar que a pesquisa se consolidou em um momento pandêmico, frente à expansão mundial da COVID 19. Momento histórico e ainda em fase de experiência prática, conscientização e sistematização dos sentimentos em relação a um horizonte de futuro, em todos os âmbitos. Considerando os procedimentos técnicos para o desenvolvimento da pesquisa, o estudo foi delineado sob a forma de estudo de caso, consonante com a metodologia aplicada, pois tem como objetivo o encontro de uma solução para um problema social, uma realidade circunstancial, valendo-se de uma aplicação prática de conhecimentos. (Pradanov, 2013)

No que diz respeito aos dados provenientes da pesquisa, esses foram obtidos através das narrativas com animações produzidas por três discentes, com o uso do software Scratch. Os discentes, com idades entre treze e quinze anos, sendo dois meninos e uma menina, pertenciam a diferentes redes de ensino do Rio Grande do Sul (interior e capital), dois deles de diferentes redes particulares confessionais e um de escola pública RENOTE 
estadual, da cidade de Porto Alegre. A partir do envio por e-mail da proposta de coleta de dados e de assinaturas nos termos de consentimento e assentimento da pesquisa, os discentes desenvolveram e retornaram suas produções entre os meses de setembro e novembro de 2020. Cada uma das produções foi constituída na plataforma do software Scratch, disponibilizando à autora da pesquisa o link da produção correspondente.

Face à subjetividade dos dados, considerou-se a análise qualitativa e a adoção da técnica de análise de conteúdo como as mais adequadas. A análise de conteúdo, segundo Bardin (1977, p. 46), objetiva "a manipulação de mensagens (conteúdo e expressão desse conteúdo), para evidenciar os indicadores que permitam inferir sobre uma outra realidade que não a da mensagem”. Para tanto, faz-se necessária a adoção de seu método, organizado em fases: pré-análise; exploração de material e tratamento dos resultados.

Para a organização e categorização do material submetido à análise de conteúdo, a pesquisa valeu-se de uma análise indutiva e dedutiva conceitualmente, uma vez que trata de duas questões objetivas - escola e pandemia - em relação a questões subjetivas modos de ser (aluno), estar (em casa/escola virtual) e projetar (o que seria/o que está sendo/como será). Assim, subsidiada pelos autores, organizou-se a seguinte figura de referência para análise de conteúdo das narrativas digitais:

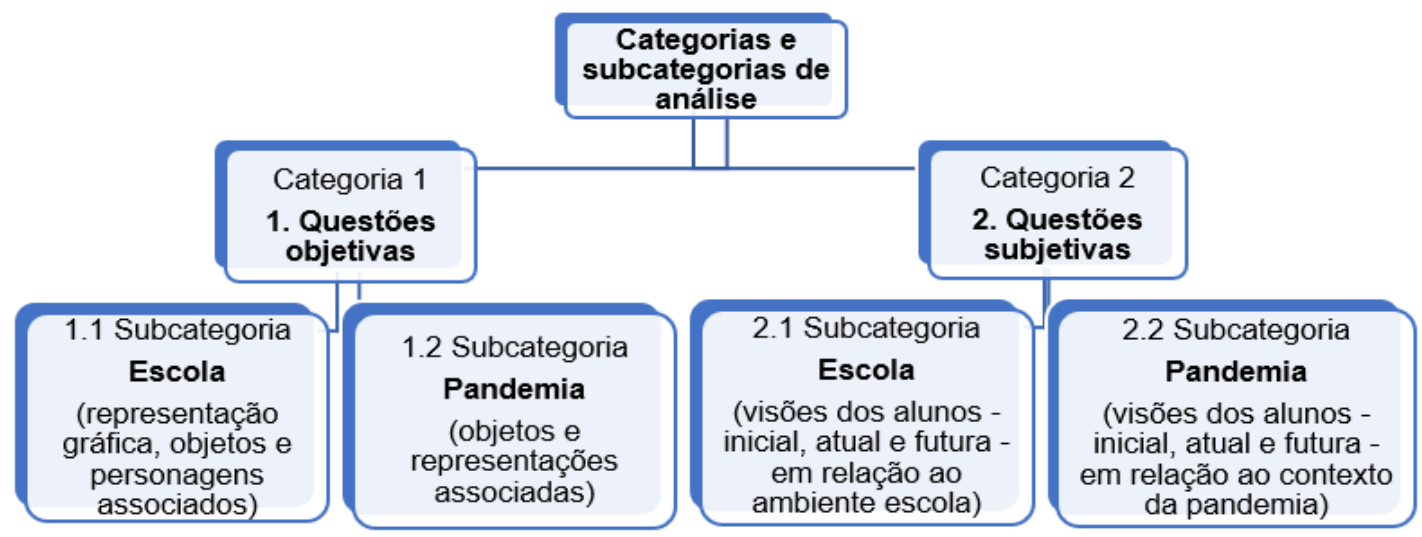

Figura 1 - Categorização dos dados da análise qualitativa de conteúdo

Fonte: Elaborada pelas autoras (2020)

A partir do equacionamento do problema de pesquisa e dos resultados apresentados de acordo com o quadro, evidenciou-se possíveis ações emergentes para atuação do $\mathrm{OE}$.

\section{Resultados e discussão}

No segundo semestre de 2020 foram iniciadas as buscas de uma turma ou grupo de alunos que pudessem colaborar na pesquisa. Desta forma, foram realizados contatos com coordenador pedagógico e docentes de três diferentes instituições da rede particular de ensino de Porto Alegre, assim como um docente da rede estadual da cidade de Santa Maria. Infelizmente, os contatos foram infrutíferos por diferentes razões: experiência discente com software apenas para introdução de conceitos matemáticos ou sua utilização tendo a figura do professor como escriba; recusa pela temática "pandemia", temendo sofrimentos psíquicos, ou ainda, indisponibilidade dos alunos. Face à dificuldade em encontrar alunos que detivessem conhecimento e autonomia para a atividade de programação com o software, a situação foi discutida com colegas de estudo. A partir daí, sujeitos de seus círculos familiares ou institucionais foram mobilizados. 
Assim, para desenvolvimento do estudo de caso, três alunos ${ }^{4}$ foram convidados a contar, através da utilização do software Scratch, suas expectativas escolares anteriores à pandemia e pós-pandemia, bem como a convivência atual com as atividades escolares remotas. $\mathrm{O}$ grupo de alunos foi composto por dois meninos e uma menina, com idades entre treze e quinze anos. Dois dos alunos pertenciam a redes particulares distintas de ensino, mas ambas de cunho confessional, uma delas localizada na capital e a outra na cidade de Erechim. Já o terceiro aluno pertencia à rede estadual de Porto Alegre.

Inicialmente, foram realizados contatos com os responsáveis pelos jovens, explicando a proposta e a necessidade de concordância e assinaturas no termo de consentimento e assentimento (aluno). Após a manifestação de concordância pelas partes, a solicitação da atividade foi enviada para o e-mail disponibilizado, sendo acordado o retorno da atividade através da disponibilização do link do projeto da plataforma Scratch, também via e-mail. O desenvolvimento e o retorno das atividades ocorreram entre os meses de setembro e novembro de 2020, tendo em vista a dificuldade de encontro de sujeitos com as características requeridas pela pesquisa e acúmulo de atividades remotas demandadas por suas escolas.

O aluno A, através de seu personagem composto por um boneco palito, atendeu a demanda com poucos quadros de imagens, porém, expressivas:

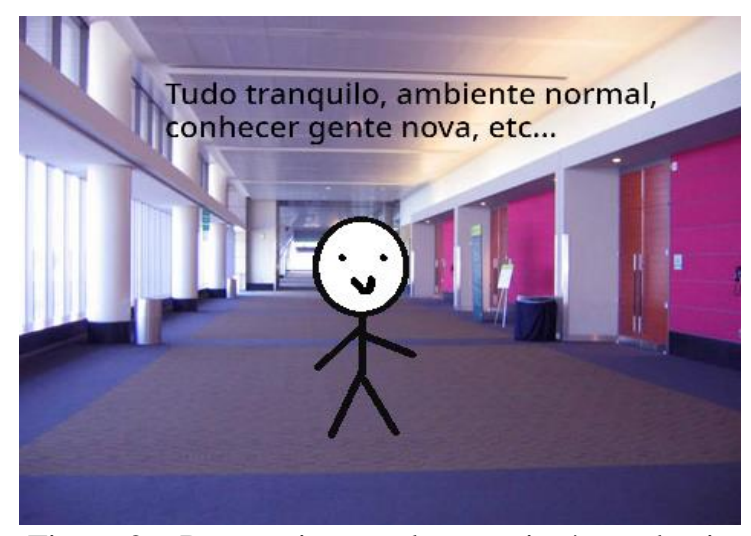

Figura 2 - Perspectiva escolar anterior à pandemia

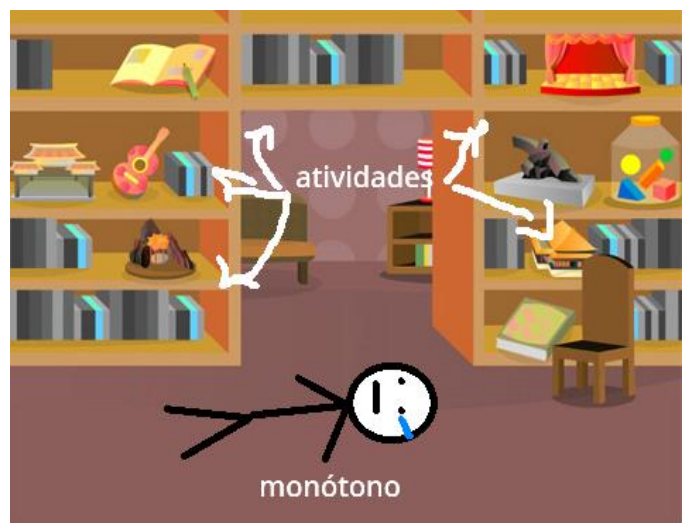

Figura 3 - Durante a pandemia, com atividades remotas

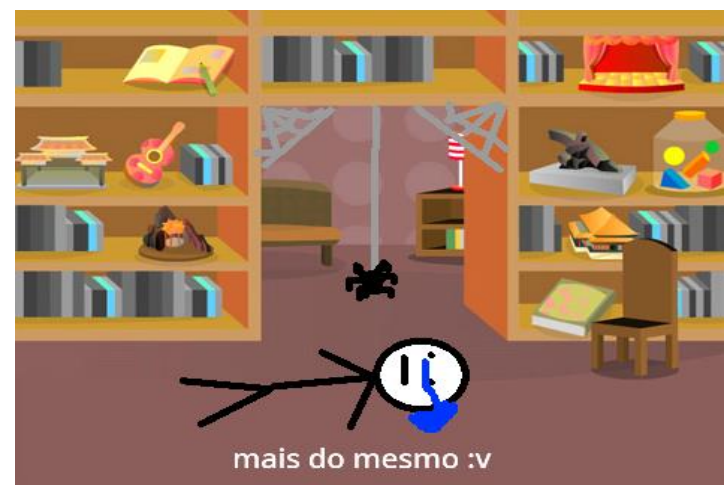

Figura 4 - Perspectiva escolar após a pandemia

Fonte: Aluno A

Já o aluno B optou pela utilização de um pinguim como personagem principal. Valeu-se de maior quantidade de quadros, movimentos e balões de fala para expressar

\footnotetext{
${ }^{4}$ Para fins de preservação das identidades e cumprimento dos termos de assentimento e consentimento assinados pelos alunos e seus responsáveis, nessa pesquisa, os alunos serão identificados pelas letras A, B e C. 
sua percepção sobre o ano escolar. De forma sintética, entende-se que as imagens a seguir revelam suas ideias centrais.

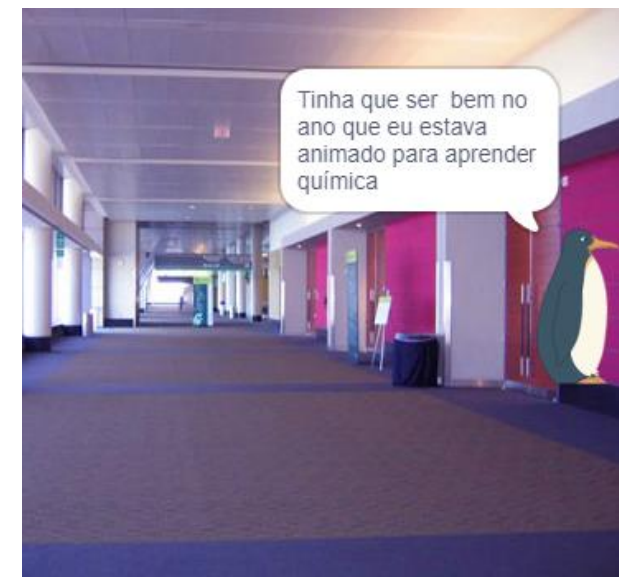

Figura 5 - Perspectiva antes da pandemia

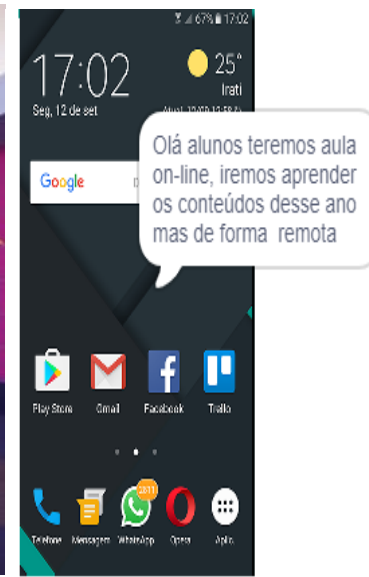

Figura 6 - Durante a pandemia, com atividades remotas

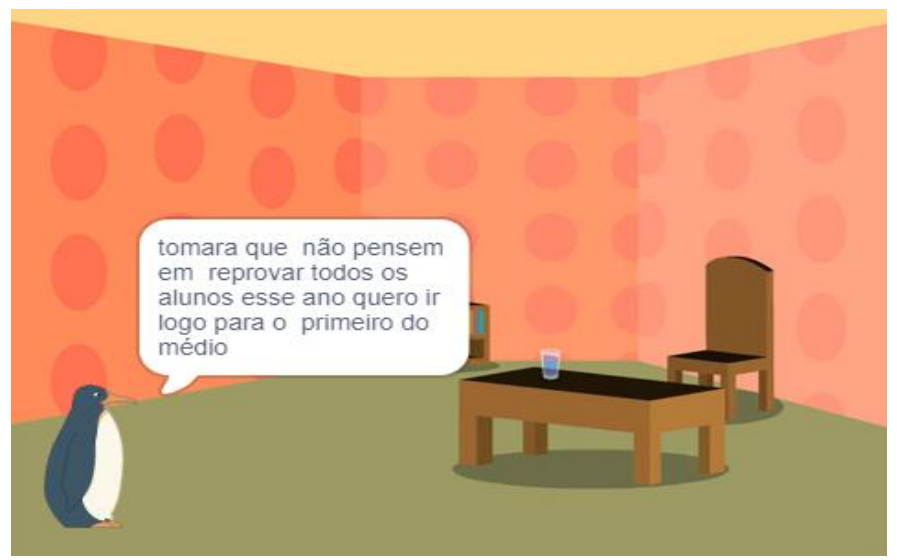

Figura 7 - Perspectiva escolar após a pandemia

Fonte: Aluno B

Por fim, o aluno $\mathrm{C}$ utilizou, possivelmente, um avatar para representar sua própria imagem. Na animação, há o emprego de um título "Quarentenados", instruções de manuseio para troca dos quadros, maior número de emprego deles, movimentos, uso de balões de fala e inclusão de um segundo personagem. Percebe-se um maior detalhamento na composição do personagem principal, a exemplo da camiseta com identificação da escola. A seguir, alguns trechos da animação que parecem expor suas ideias centrais.
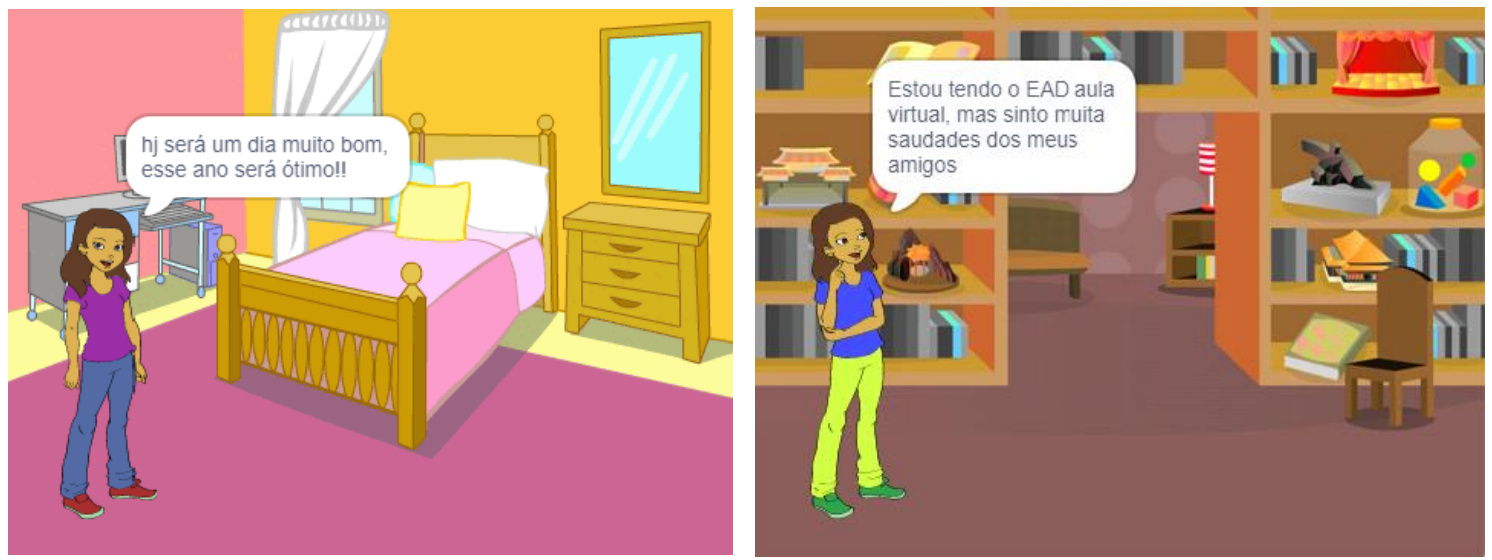

Figura 8-Perspectiva escolar anterior à pandemia Figura 9-Durante a pandemia, com atividades remotas 


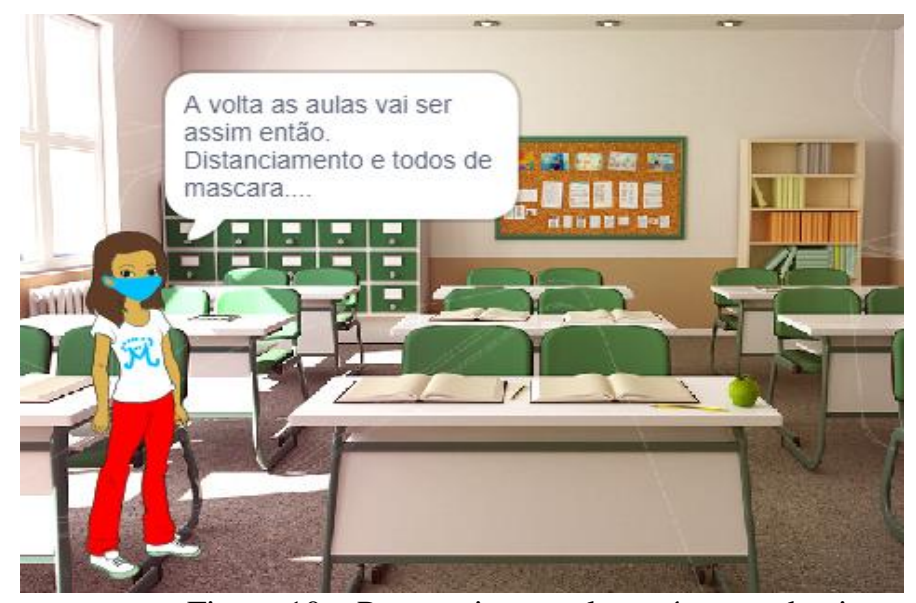

Figura 10 - Perspectiva escolar após a pandemia Fonte: Aluno C

Os dados de todas as produções foram agrupados de acordo com as categorias previamente estabelecidas para melhor visualização e análise das três narrativas digitais animadas. Assim, iniciando a análise a partir da primeira categoria - Questões objetivas, a qual abarca as subcategorias Escola e Pandemia encontraremos elementos que dizem respeito às representações gráficas, objetos, personagens e imagens associadas ao ambiente escola e suas relações com as diversas visões dos alunos - inicial, atual e futura nesse ambiente. Assim, analisando isoladamente o que diz respeito à Escola, houve, curiosamente, a utilização de um mesmo cenário inicial por todos os participantes. A representação de um espaço amplo, similar a um hall de entrada que dá acesso a muitas portas. Nesse sentido, vale lembrar que os alunos não são colegas de escola, tão pouco de uma mesma rede de ensino, o que tende a aproximar a uma representação imagética e não literal. Na mesma subcategoria, figuram os objetos relacionados e, mais uma vez, há uma constância entre os três na associação do objeto livro, seja no período atual como futuro. No caso específico do aluno C, há uma prospecção futura em uma sala de aula habitual, com a presença de todos os objetos escolares característicos, diferindo-se apenas pela presença de máscara de proteção no avatar confeccionado. Também chama a atenção a segunda incidência de mesma escolha de cenário para representação da atual fase, no ambiente doméstico, pelos alunos A e B. Ou seja, o traspasse de um ambiente anteriormente amplo para um cômodo com a acumulação de muitos materiais escolares, restrito a prateleiras e apenas uma cadeira. Representação que sugere, de fato, uma questão do isolamento. Questão também similarmente representada pelo aluno B, porém, com um número inferior de elementos.

A instituição escola possui uma capacidade de reconhecimento mundial, seja por certa constância arquitetônica, seja por seus seculares instrumentos, como livro, quadro, giz, mesa e cadeira. Cenário que se mantem no imaginário dos sujeitos da pesquisa, no entanto, o sujeito B já dá pistas de um elemento novo, utilizado, sobretudo, na pandemia, o instrumento digital smartfone. Sinalizando, talvez, uma futura transição entre secular estrutura impressa para a digital. Já no que diz respeito a personagens associados, apenas os sujeitos A e C introduzem a representação gráfica ou mencionam "amiga", "amigos" ou "gente nova", o que revela seus laços de afeto e socialização. Xavier (2008), ao analisar o tipo de estudante, retoma Dubet, teórico da Sociologia da Educação, em estudo sobre o colégio e os adolescentes, o qual aponta para a vivência de jovens dentro da escola sob diferentes culturas, a escolar e sua própria cultura:

Os jovens, principalmente os de classe popular, têm o espaço escolar como um dos únicos espaços de vivência, de convivência. A escola é hoje o espaço de 
vivência para a juventude não contemplada em outras instâncias nas políticas públicas. A sociedade não tem, em sua organização, outros lugares próprios para a juventude nem para as crianças (Xavier, 2008, p. 15).

$\mathrm{O}$ apontamento da autora parece ir ao encontro, principalmente, de $\mathrm{C}$, ao mencionar o início de um novo ano escolar como uma oportunidade de estabelecer novos contatos. Nesse sentido, retomando o cenário vivido, de isolamento ou distanciamento social, essas possibilidades se tornaram ainda mais restritas, senão, inviáveis. Logo, um impacto significativo e negativo para o estabelecimento de novas relações sociais dessa faixa etária.

Já na segunda subcategoria, Pandemia, foi representada pelo sujeito $C$ através da máscara de proteção, talvez, o ícone dessa pandemia. Seguido do sujeito B, ambos trouxeram em suas narrativas as mensagens amplamente divulgadas e requeridas pela saúde pública, como a necessidade de distanciamento. Chama a atenção a disposição para a emissão de uma mensagem positiva ao receptor, a exemplo de "fique em casa" e "logo vai passar". Algo que replica a mensagem de cuidado com o próximo e perseverança para enfrentamento do episódio atípico. Nesse sentido, retomando as frequentes falas do senso comum de que os jovens "não estão nem aí", "não se preocupam com nada e nem com ninguém", talvez sirva para refletirmos mais a respeito e depositarmos um pouco mais de esperança na juventude em desenvolvimento. Talvez desvelando a generalização para possibilidade de encontro de indivíduos conscientes, atentos às mensagens e atitudes que nós próprios emanamos sobre a vida em sociedade.

Avançando para a segunda categoria, Questões subjetivas, em sua primeira subcategoria Escola, temos as diversas visões dos alunos - inicial, atual e futura - em relação ao ambiente escola onde, para fins de avaliação, foram ponderadas as manifestações com a tipificação alta, média ou baixa, seguidas das razões que indicam convergência para o enquadramento. Entendeu-se que havia, em maioria, uma alta perspectiva, seja em razão do desejo de um novo conteúdo ou projeção positiva para a totalidade do ano. Contudo, o aluno A explicita uma baixa expectativa, justificada pela manutenção de "normalidade" e monotonia do ambiente, que vai sendo sustentada no decorrer da animação, seja pelas mensagens escritas como pelas expressões representadas. Nesse sentido, mais uma vez Xavier (2008, p. 16) nos auxilia ao pensarmos sobre a cultura jovem, trazendo como necessário o questionamento acerca de como a escola pode fazer a "[...] transição da cultura da geração anterior, que também não é monolítica, algo que possa interessar aos jovens estudantes".

Já quanto à vivência escolar atual, tipificada como positiva, negativa ou indiferente, admitiu-se entre média a baixa a relação com a aprendizagem, face às representações de sentimentos negativos como choro, monotonia, saudade dos amigos e oscilação entre alegria com o ócio e relativização quanto saudade dos amigos e oscilação entre a alegria com o ócio e a relativização quanto à aprendizagem: "pelo menos vamos aprender alguma coisa" (aluno B). Assim, considerando o transpasse da atuação do OE com as relações de aprendizagem, uma vez que pretende o desenvolvimento integral e harmonioso do educando, os elementos fornecidos pelos sujeitos podem servir de alerta a fatores de interferência negativa para o estabelecimento da aprendizagem. Quanto à perspectiva futura, adotou-se uma classificação em grau de intensidade entre alta, média ou baixa, seguida das razões que as justificam, entendeu-se uma oscilação entre média a baixa expectativa para o retorno escolar. O sujeito B parece centrar-se exclusivamente no desejo de avanço na etapa educacional. Já o sujeito $\mathrm{C}$ sinaliza os aspectos de um retorno diferenciado, adaptativo, pois entende que as medidas de prevenção deverão ser mantidas, sustentando um sentimento de credibilidade que, em breve, a normalidade retornará. A representação de menor expectativa explicitou-se no sujeito A, ao manter sua narrativa V. $19 \mathrm{~N}^{\mathrm{o}} 1$, julho, 2021 DOI: https://doi.org/10.22456/1679-1916.118484 RENOTE 
de desânimo, aumento de tristeza e finalizada com elementos agregadores em um quadro que parece representar uma relação estática, hermética, de abandono ou até mesmo aterrorizante. Elementos que, sem uma intervenção direta com o aluno, não poderemos avaliar com segurança sua real motivação. Contudo, podemos inferir, através das representações do personagem e de suas falas, que a escola não figura como elemento motivador, desafiante e construtor. Pelo contrário, sugere algo imutável, que condiciona, machuca e aterroriza, restando, talvez, como válvula de escape, apenas a oportunização de socialização, de "conhecer gente nova", fato mencionado no único quadro expresso com um sorriso.

$\mathrm{Na}$ segunda subcategoria, Pandemia, foram analisadas as diversas visões dos alunos - inicial, atual e futura - em relação ao contexto da pandemia. Compreendese que, forma geral, a pandemia consolidou um cenário de mudanças tecnológicas de ensino e aprendizagem escolar, inovando no acesso, mas mantendo-se carente de sentido. Parece ter seguido em uma lógica conteudista e pouco relacional ou interativa. O contexto pandêmico também trouxe incertezas e angústias, seja no que diz respeito à possibilidade de aprovação ou reprovação escolar, como pelo seu tempo de duração. Contudo, o impacto possivelmente mais significativo para os três sujeitos parece ter sido o desfavorecimento de elos de amizades escolares. Ou seja, a possibilidade de interação social favorecida pelas atividades presenciais, inoperante na atualidade, parece ter representado um grande prejuízo. No contexto relacional com a aprendizagem, é sabido que esse fator pode afetá-la negativamente. Quando considerada a faixa etária desses jovens, o impacto negativo também é percebido, uma vez que, para muitos deles, o espaço social é restrito ao ambiente escolar. Desse modo, como não refletir sobre as funções sociais da escola: ela se restringiria tão somente à concessão de passagens de nível? Encontro com amigos? Seria possível ser feliz dentro da atual cultura escolar?

Quando retomamos a questão do compromisso fundamental da escola, Xavier (2008, p. 17) igualmente corrobora com Pascoal (2008), ao mencionar que:

\begin{abstract}
O compromisso fundamental da instituição escolar continua sendo com a aquisição e a produção de conhecimentos e com o desenvolvimento harmonioso da criança e do jovem. Para tal, os projetos políticos pedagógicos, os planos de estudos e os planos de trabalho para cada professor ou professora devem ser pensados tendo em vista promover tal desenvolvimento. [...] Precisa a escola ser também local para a produção de jovens mais sadios, mais bonitos, mais confiantes em si, mais felizes.
\end{abstract}

As autoras pactuam a ideia da escola com um compromisso social de formação humana, mas que não se limita à tradicional "transmissão de conteúdos". Pelo contrário, trata-se de um compromisso de maior dimensão, na medida em que resgata, acolhe e respeita as vivências, os conhecimentos e as singularidades. Entendem a escola como um espaço sociocultural em constante transformação e construção. Entendendo dessa forma o espaço escolar, o OE passa a ser elo fundamental para manutenção desse local dinâmico de formação humana e cultural.

\title{
4. Considerações finais
}

Este trabalho apresentou um estudo de caso envolvendo alunos da EB, sendo utilizado o software Scratch, disponível em uma plataforma gratuita de programação de computadores para alunos a partir de 8 anos de idade. Vale ser destacado a dificuldade inicial para a concretização da pesquisa, visto que ocorreu em um período de isolamento ou distanciamento social em virtude da COVID 19. Associado a esse fator, esteve a fluência digital no software para capacidade de programação autônoma, pois foi V. $19 \mathrm{~N}^{\mathrm{o}} 1$, julho, 2021 RENOTE 
necessária em razão da virtualização da proposta e obtenção da expressão das subjetividades. Por outro lado, essa busca específica evidenciou a carência de práticas pedagógicas, tanto com o uso do software, como para um objetivo diverso ao ensino da lógica para progressos em matemática.

Apesar das adversidades, acredita-se que esse estudo contribuiu para evidenciação de que práticas pedagógicas virtuais, com tecnologia digital, mais próximas às culturas juvenis, tem potencial para agregar ações sistêmicas de orientadores educacionais. Tratou-se de uma prática que envolveu conhecimentos curriculares, mas também a exploração das subjetividades, com vistas a uma ação estratégica e diagnóstica. Os alunos $\mathrm{A}, \mathrm{B}$ e $\mathrm{C}$, oriundos de redes escolares distintas, além de comprovarem a hipótese de trabalho, também sinalizaram movimentos positivos da escola pública, uma vez que um deles é integrante da rede estadual, demonstrando uma ação pedagógica eficiente e efetiva quanto à utilização dessa tecnologia.

Para fins de trabalhos futuros, acredita-se que a etapa diagnóstica seguida de uma entrevista com os sujeitos é interessante, caso haja o interesse em esmiuçar mais detalhadamente os personagens, fatos e sentimentos que compuseram as narrativas digitais. Por fim, salienta-se a emergência na formação de profissionais - orientadores educacionais - com perfil atualizado, bem como de outros profissionais da educação e/ou da saúde, face às demandas atuais da escola; incremento da produção científica da área e simetria entre os agentes escolares para ações de desenvolvimento verdadeiramente integral dos sujeitos.

\section{Referências Bibliográficas}

BARDIN, Laurence. Análise de conteúdo. Lisboa: Edições 70, 1977.

BOCK, Ana Maria. A psicologia e as psicologias. Digital Source. Disponível em < http://groups-beta.google.com/group/digitalsource> Acesso em 01 dez. 2020.

BRASIL. Ministério de Educação. Base Nacional Comum Curricular. Brasília, DF. Disponível

$<$ http://portal.mec.gov.br/index.php?option=com_docman\&view=download\&alias=796 11-anexo-texto-bncc-aprovado-em-15-12-17-pdf\&category_slug=dezembro-2017-

pdf \&Itemid=30192> > Acesso em: 30 Mar. 2020.

BRASIL. Decreto n. 72.846, de 26 de setembro de 1973. Regulamenta a Lei ${ }^{\circ}{ }^{5}$.564, de 21 de dezembro de 1968, que provê sobre o exercício da profissão de orientador educacional.

CORBELLINI, Silvana. BNCC: NOS TRILHOS DO TREM. Revista ENSIN@UFMS, Três Lagoas/MS, v. 1, n. 5, p. 1-163, dezembro 2020. Disponível em: https://periodicos.ufms.br/index.php/anacptl/article/view/11311 Acesso em: 20 de janeiro de 2021.

GIL, Antônio Carlos. Como elaborar projetos de pesquisa. 3. ed. - São Paulo: Atlas, 1991.

PASCOAL, Miriam; HONORATO, Eliane Costa; ALBUQUERQUE, Fabiana Aparecida. O orientador educacional no Brasil. Educação em Revista. Belo Horizonte, n. 47, p. 101-120. jun. 2008.

PRADANOV, Cleber Cristiano. Metodologia do trabalho científico [recurso eletrônico]: métodos e técnicas da pesquisa e do trabalho acadêmico / Cleber Cristiano Prodanov, Ernani Cesar de Freitas. - 2. ed. - Novo Hamburgo: Feevale, 2013.

XAVIER, Maria Luisa. Escola e sala de aula - mitos e ritos: um olhar pelo avesso do avesso. In. Ávila, Ivany Souza. Escola e mundo contemporâneo - novos tempos, novas exigências, novas possibilidades. 2. Ed. - Porto Alegre: Editora da UFRGS, 2008. 